\title{
Effects of freeze-thaw on soil erosion processes and sediment selectivity under simulated rainfall
}

\author{
WANG Tian', LI Peng ${ }^{1}$, REN Zongping ${ }^{1}$, XU Guoce ${ }^{1 *}$, LI Zhanbin ${ }^{1,2}$, YANG Yuanyuan ${ }^{1}$, \\ TANG Shanshan ${ }^{1}$, YAO Jingwei ${ }^{1}$ \\ ${ }^{1}$ State Key Laboratory Base of Eco-Hydraulic Engineering in Arid Area, Xi'an University of Technology; Xi'an 710048, \\ China; \\ ${ }^{2}$ State Key Laboratory of Soil Erosion and Dry-land Farming on the Loess Plateau, Institute of Soil and Water Conservation, \\ Chinese Academy of Sciences and Ministry of Water Resources, Yangling 712100, China
}

\begin{abstract}
The freeze-thaw (FT) processes affect an area of 46.3\% in China. It is essential for soil and water conservation and ecological construction to elucidate the mechanisms of the FT processes and its associated soil erosion processes. In this research, we designed the control simulation experiments to promote the understanding of FT-water combined erosion processes. The results showed that the runoff of freeze-thaw slope (FTS) decreased by 8\% compared to the control slope (CS), and the total sediment yield of the FTS was 1.10 times that of the CS. The sediment yield rate from the FTS was significantly greater than that from the CS after 9 min of runoff $(P<0.01)$. Both in FTS and CS treatments, the relationships between cumulative runoff and sediment yield can be fitted well with power functions $\left(R^{2}>0.98, P<0.01\right)$. Significant differences in the mean weight diameter (MWD) values of particles were observed for washed particles and splashed particles between the CS and the FTS treatments in the erosion process $(P<0.05)$. The mean MWD values under CS were smaller than those under FTS for both washed and splashed particles. The ratio of the absolute value of $a$ regression coefficient between the CS and the FTS was 1.15, being roughly correspondent with the ratio of $K$ between the two treatments. Therefore, the parameter $a$ of the power function between cumulative runoff and sediment yield could be an acceptable indicator for expressing the soil erodibility. In conclusion, the FTS exhibited an increase in soil erosion compared to the CS.
\end{abstract}

Keywords: freeze-thaw erosion; loess soil; soil erodibility; runoff; sediment size-selectivity; rainfall simulation

Citation: WANG Tian, LI Peng, REN Zongping, XU Guoce, LI Zhanbin, YANG Yuanyuan, TANG Shanshan, YAO Jingwei. 2017. Effects of freeze-thaw on soil erosion processes and sediment selectivity under simulated rainfall. Journal of Arid Land, 9(2): 234-243. doi: 10.1007/s40333-017-0009-3

\section{Introduction}

Soil erosion is one of major environmental issues (Wang et al., 2014) and seasonal freeze-thaw (FT) processes are widely reported to have resulted in severe soil erosion in the world's middle and high latitudes (Wischmeier and Smith, 1978). Seasonally-thawed surface layer (or soil) overlying frozen layers (seasonally or permanently frozen) is reportedly associated with the production of a large amount of runoff and thus with the production of a large amount of eroded sediment during snow-melting times and even under low-intensity rainfall conditions (Kirkby, 1980). In China, seasonal FT processes-affecting areas are mainly distributed in the Tibetan Plateau (Zhang et al., 2007; Jing et al., 2008). But, FT processes-related soil erosion was sufficiently documented to be rather detrimental to the agricultural economy in the northwestern

*Corresponding author: XU Guoce (E-mail: xuguoce@xaut.edu.cn)

Received 2016-03-29; revised 2016-07-05; accepted 2017-01-07

(C) Xinjiang Institute of Ecology and Geography, Chinese Academy of Sciences, Science Press and Springer-Verlag Berlin Heidelberg 2017 
and northeastern regions of China (Xu et al., 2001).

To understand soil (or surface layer) erodibility under FT conditions, many efforts have been devoted to study FT effects on soil physical properties (Øygarden, 2000; Li et al., 2013; Wang et al., 2013; Li and Fan, 2014). Generally speaking, FT processes destroy the original structures and even alter the original textures of surface layers (or soils), leading an increase in soil erodibility. Specifically, FT processes increase the soil erodibility through altering the characteristics of surface material and then rainfall and runoff provide powers to erode and transport the surface materials downstream or/and downslopes. Splashing and washing processes (Sharma, 1996) and interrill erosion processes (Issa et al., 2006) are reported to be powerful not only in erosion and transport but also in the size-selectivity of transported sediment. In terms of the size-selectivity, some studies demonstrated that finer particles can be preferentially transported (Farenhorst and Bryan, 1995; Sutherland et al., 1996; Wan and El-Swaify, 1998; Issa et al., 2006; Shi et al., 2012). But, other studies showed that coarser particles can be preferentially transported under the high rainfall intensity (Berger et al., 2010; Jiang et al., 2014). It was also reported that the water erosion- and transport-related size-selectivity was characterized by a finer-size peak and a coarser-size peak (Asadi et al., 2007a, b). The bimodal size distribution may be associated the specific erosion processes. For example, splashing was recorded to be able to detach coarser particles and washing was only able to detach finer particles (Sutherland et al., 1996; Wan and El-Swaify, 1998). However, opposite conclusions were also reported (Farenhorst and Bryan, 1995; Issa et al., 2006) and the degree of soil aggregation (Young, 1980; Meyer et al., 1992) and FT effects on the aggregation (Sahin and Anapali, 2007) were speculated to be the reasons behind the reported contradictions.

The present study was designed to promote our understanding of the FT processes and the associated soil erosion occurring in the loess hilly regions within the middle reach of the Yellow River through laboratory-controlled simulation experiments. The middle reach of the Yellow River is characterized by a relatively long winter with 105-125 days of freezing temperature (i.e., below $0^{\circ} \mathrm{C}$ ) and also by a relatively fast warming (or thawing) spring, and thus FT-related soil erosion on the hilly loess slopes is quite severe (Wang, 2004; Wang et al., 2013). Normally, the FT-dominated erosion was both immediately preceded and also succeeded by water-dominated erosion, and the combined processes between water and FT (freeze-thaw) come into effect during the transitions between water-dominated erosion periods and FT-dominated erosion periods (Wischmeier and Smith, 1978). However, most relevant researchers have focused either on FT processes altering the surface soil properties or on water erosion processes, and few have considered the combined effects of both (Wang et al., 2013). So that, FT-water combined erosion processes and the associated size-selecting processes are well not understood yet. Therefore, we analyzed the erosion processes on freeze-thaw slopes (FTS) and compared the processes with those on control slopes (CS) by laboratory-controlled simulation experiments. The aims of this study were: (1) to analyze the eroding and depositing processes and also the size-selecting processes under FTS and under CS treatments; and (2) to evaluate the differences of soil erodibility between FTS and CS treatments. And, the soil erodibility was assessed by calculating the soil erosion factor $K$ using the Universal Soil Loss Equation (USLE) (Wischmeier and Smith, 1978).

\section{Materials and methods}

\subsection{Experimental design and treatment}

Simulated rainfall experiments were conducted in the State Key Laboratory of Eco-Hydraulic Engineering at Xi'an University of Technology in China in April 2015. The simulated rainfall system used in this study consisted of more than 1300 hypodermic needles attached to a $0.9 \mathrm{~m}$ (length) and $0.45 \mathrm{~m}$ (width) bottom plate (Fig. 1) that could produce raindrops being quite similar to the naturally-occurred raindrops. The soil-testing bin was $0.9 \mathrm{~m}$ long and $0.45 \mathrm{~m}$ wide. 

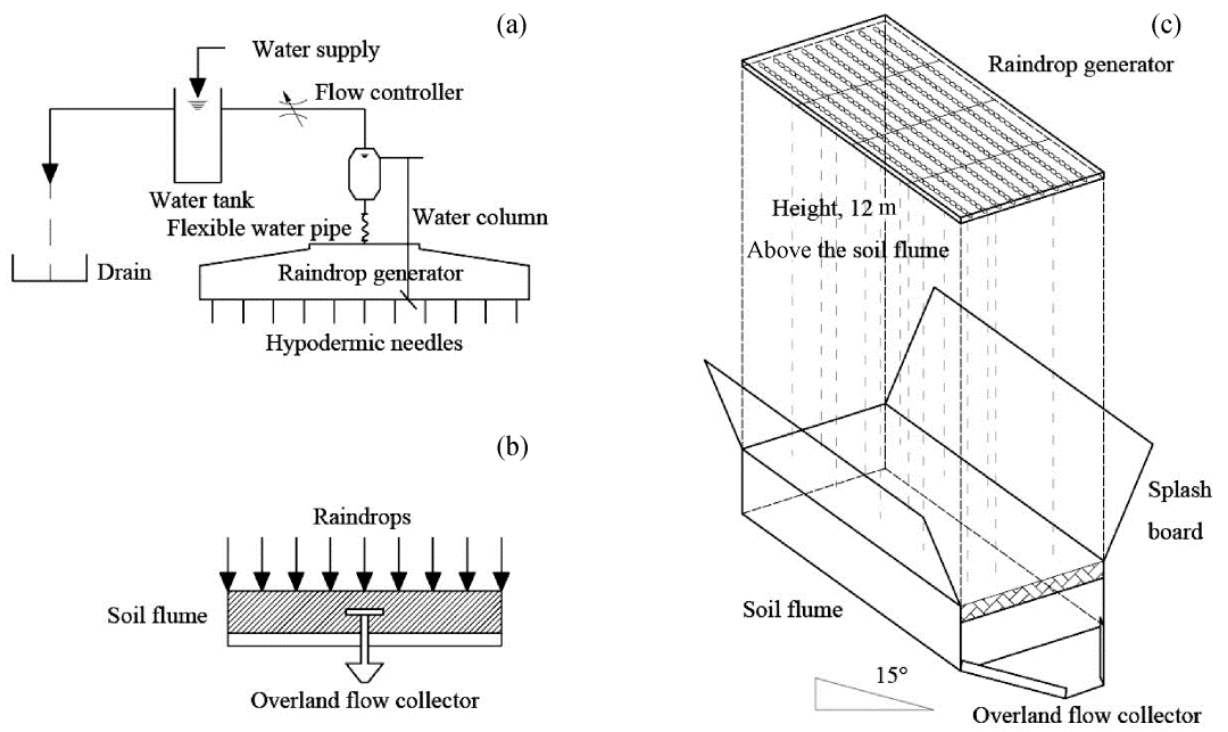

Fig. 1 Schematic diagram of the simulated rainfall system: the overall structure of the system (a); the structural relationship among raindrop, soil flume and overland flow collector (b); the details of raindrop generator (c)

First, a 2-cm-thick layer of field-collected loamy sand was laid in the bottom of the bin to keep the soil drainage conditions similar to those of the natural slope. Next, the upper part was filled with loess of $10-\mathrm{cm}$ thick. The slope of the flume was adjustable with a fixed slope of $15^{\circ}$. The moisture of the testing bin (i.e., loess) was controlled at about $15 \%$ and the dry soil bulk density was maintained at $1.25 \mathrm{~g} / \mathrm{cm}^{3}$ (Table 1).

Table 1 Observed rainfall intensity, soil bulk density and porosity under freeze-thaw slopes (FTS) and under control slopes (CS)

\begin{tabular}{cccc}
\hline Treatment & $\begin{array}{c}\text { Mean rainfall intensity } \\
(\mathrm{mm} / \mathrm{min})\end{array}$ & $\begin{array}{c}\text { Mean soil bulk density } \\
\left(\mathrm{g} / \mathrm{cm}^{3}\right)\end{array}$ & $\begin{array}{c}\text { Soil porosity } \\
(\%)\end{array}$ \\
\hline CS & $1.03 \pm 0.005$ & $1.25 \pm 0.006$ & $52.70 \pm 0.33$ \\
FTS & $1.01 \pm 0.002$ & $1.21 \pm 0.003$ & $53.10 \pm 0.19$ \\
\hline
\end{tabular}

Note: All data are means \pm standard deviation.

A rainfall intensity of $1 \mathrm{~mm} / \mathrm{min}$ was maintained by controlling the flow discharge in the pipe using a flow controller (Ran et al., 2012). A runoff collection device was installed at the bottom of the bin to collect runoff and sediment (Fig. 1). Runoff and sediment samples were collected in pails of known volume at 3-min intervals for each treatment (FTS or CS). Rainfall intensity was measured for each replicate and never deviated from the target intensity by more than $5 \%$. Simulated rainfall was applied for $60 \mathrm{~min}$ to both the FTS and CS treatments and three replicates were conducted for all experiments. Splash particles were collected on plastic boards $(1.0 \mathrm{~m} \times 0.3$ $\mathrm{m})$ and covered with filter paper. Two splash boards were set on both side of the soil flume, intersecting at a $10^{\circ}-20^{\circ}$ angle. The splash particles were collected immediately before runoff appearance and at 10-min intervals after runoff appearance. The FTS was constructed as follows: the flume filled with soil was first wrapped with heat-insulating material to maintain the needed freezing from the top to the bottom. Next, the soil-filled flume was packed in an ultra-low-temperature freezer at a $15^{\circ}$ slope. The soil was completely frozen at a temperature of $-20.0^{\circ} \mathrm{C}$ for $24 \mathrm{~h}$ and then thawed at room temperature for $24 \mathrm{~h}$. The room temperature during the experiments was maintained between $18.0^{\circ} \mathrm{C}$ to $20.0^{\circ} \mathrm{C}$.

\subsection{Measurements and data analyses}

The soil particle size was measured by laser diffraction using a Mastersizer 2000 particle-size analyzer (Malvern Instruments, Malvern, England; Xu et al., 2013). The ring method was used to 
measure the soil bulk density, and the soil water content was measured by the gravimetric method. The original soil particle sizes are listed in Table 2.

Table 2 Mechanical composition of the original soil

\begin{tabular}{cccc}
\hline & Clay & Silt & Sand \\
\hline Mean value (\%) & 1.13 & 92.87 & 6.00 \\
Standard error & 0.12 & 0.34 & 0.24 \\
\hline
\end{tabular}

In this research, soil erodibility was obtained from rainfall simulation experiments conducted in the laboratory. The soil erodibility factor $K$ can be calculated as follows (Yu et al., 2006; Wang et al., 2014):

$$
K=A /(R \times L S) .
$$

Where $K(\mathrm{~kg} \cdot \mathrm{h} /(\mathrm{MJ} \cdot \mathrm{mm}))$ is the soil erodibility; $A\left(\mathrm{~kg} / \mathrm{m}^{2}\right)$, the amount of soil loss; $R$ $\left(\mathrm{MJ} \cdot \mathrm{mm} /\left(\mathrm{m}^{2} \cdot \mathrm{h}\right)\right)$, the rainfall erosivity factor; and $L S$, the slope length (i.e., gradient factor). It should be noted that the management practice factors (C and P) of the USLE were set to 1 .

The size distribution of the eroded material was expressed as the mean weight diameter (MWD), which can be calculated using the equation below (Le Bissonnais, 1996):

$$
M W D=\frac{\sum_{1}^{7} \overline{\chi_{i}} \omega_{i}}{100} \text {. }
$$

Where $\overline{\chi_{i}}(\mathrm{~mm})$ is the mean diameter of the $i$ size class and $\omega_{i}(\%)$ is the percentage of particles of the $i$ size class. A total of seven size classes were used $(<0.005,0.005-0.1,0.1-0.2,0.2-0.5$, $0.5-1,1-2$ and $>2 \mathrm{~mm}$ ).

The soil porosity was calculated as follows (Hunt et al., 1991):

$$
P=\left(1-\frac{d_{i}}{\rho}\right) \times 100 \% \text {. }
$$

Where $P(\%)$ is the soil porosity; $d_{i}\left(\mathrm{~g} / \mathrm{cm}^{3}\right)$, the soil bulk density; $\rho\left(\mathrm{g} / \mathrm{cm}^{3}\right)$, the soil density and the commonly-used value is $2.65 \mathrm{~g} / \mathrm{cm}^{3}$.

$$
\begin{aligned}
& V_{d}=v \times 10 /(c \times t) . \\
& i_{d}=i \times \cos \alpha-10 \times v /(c \times t) .
\end{aligned}
$$

Where $V_{d}(\mathrm{~mm} / \mathrm{min})$ is the runoff rate; $v(\mathrm{~mL})$, the runoff volume; $c\left(\mathrm{~m}^{2}\right)$, the simulation area; $t$ (min), the runoff time; $i_{d}(\mathrm{~mm} / \mathrm{min})$, the infiltration rate; $i(\mathrm{~mm} / \mathrm{min})$, the rainfall intensity; and $\alpha$ $\left({ }^{\circ}\right)$, the slope gradient.

Statistical analyses were performed with SPSS 16.0 for Windows. An analysis of variance (ANOVA) test was performed to determine the treatment effects on the measured variables. The data were generated using the OriginPro 8.5 and CAD 2010.

\section{Results}

\subsection{Runoff, infiltration and sediment yield}

The runoff rates increased rather rapidly during the initial stage of runoff production and increased rather slowly after about $15 \mathrm{~min}$ under both treatments (FTS and CS) for the same conditions (Fig. 2a): rainfall intensity, rainfall duration, initial soil water content (before freezing) and slope gradient. The runoff rate of the CS ranged from 0.13 to $0.50 \mathrm{~mm} / \mathrm{min}$ with a mean value of $0.44 \mathrm{~mm} / \mathrm{min}$ and the runoff rate of the FTS from 0.12 to $0.46 \mathrm{~mm} / \mathrm{min}$ with a mean value of $0.40 \mathrm{~mm} / \mathrm{min}$, with the runoff rate of the CS being systematically higher than that of the FTS.

The infiltration rates were almost identical under both treatments (FTS and CS) and declined rapidly during the initial stage of runoff production (Fig. 2b). And, the rates under both treatments declined rather slowly after about $10 \mathrm{~min}$. The infiltration rate under CS ranged from 0.47 to 0.83 
$\mathrm{mm} / \mathrm{min}$ with a mean value of $0.53 \mathrm{~mm} / \mathrm{min}$ and the infiltration rate of the FTS from 0.51 to 0.85 $\mathrm{mm} / \mathrm{min}$ with a mean value of $0.56 \mathrm{~mm} / \mathrm{min}$, with the rate under CS being systematically lower than that under FTS.
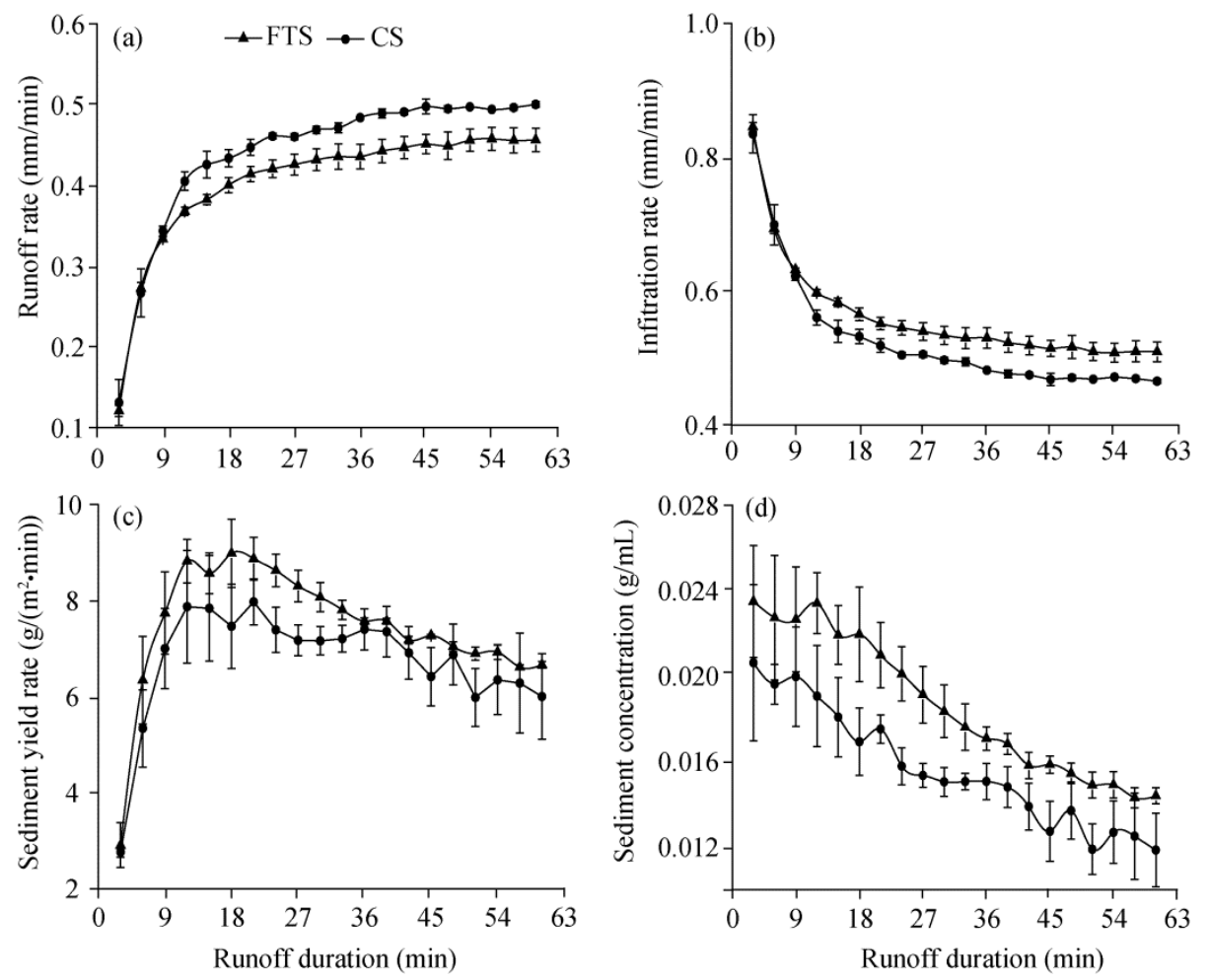

Fig. 2 Temporal variations in runoff rate (a), infiltration rate (b), sediment yield rate (c) and sediment concentration (d) under freeze-thaw slopes (FTS) and control slopes (CS). Bars indicate standard errors.

Sediment yield rate is another important parameter for describing the slope erosion processes. The sediment yield rates were rapidly rising during the initial stage of runoff production and gradually declined after about 10 min under both treatments (FTS and CS; Fig. 2c). The sediment yield rate ranged from 2.76 to $7.98 \mathrm{~g} /\left(\mathrm{m}^{2} \cdot \mathrm{min}\right)$ with a mean of $6.74 \mathrm{~g} /\left(\mathrm{m}^{2} \cdot \mathrm{min}\right)$ under CS and from 2.91 to $8.99 \mathrm{~g} /\left(\mathrm{m}^{2} \cdot \mathrm{min}\right)$ with a mean of $7.44 \mathrm{~g} /\left(\mathrm{m}^{2} \cdot \mathrm{min}\right)$ under FTS, with the rate under FTS being systematically higher than that under CS. It should be particularly noted that the difference of sediment yield rates between FTS and CS became larger and larger during the initial stage of runoff production (approximately from 3 to $15 \mathrm{~min}$ ), remained to be rather large during the middle stage (approximately from 15 to $30 \mathrm{~min}$ ), and maintained at an intermediate level during the final stage (approximately from 30 to $60 \mathrm{~min}$ ).

The sediment concentrations under both FTS and CS exhibited gradual declining trends from the runoff initiation onward and the concentration under FTS was systematically higher than that under CS (Fig. 2d). The sediment concentration ranged from 0.021 to $0.012 \mathrm{~g} / \mathrm{mL}$ with a mean of $0.016 \mathrm{~g} / \mathrm{mL}$ under CS and the concentration from 0.024 to $0.014 \mathrm{~g} / \mathrm{mL}$ with a mean of $0.018 \mathrm{~g} / \mathrm{mL}$ under FTS.

\subsection{Relationship between runoff and sediment yield under FTS and CS}

The relationship between cumulative runoff and sediment yield can be fitted by the power function $S=a W^{b}$, where $S\left(\mathrm{~g} / \mathrm{m}^{2}\right)$ is the cumulative sediment yield, $W\left(\mathrm{~L} / \mathrm{m}^{2}\right)$ is the cumulative runoff, and $a$ and $b$ are regression coefficients (Table 3 ).

All fitting equations were significant at $P<0.01$ (Table 3), and the absolute value of $a$ for the FTS was 1.15 times greater than that for the CS. For both FTS and CS treatments, the sediment 
Table 3 Regression analysis of the cumulative runoff $(W)$ and cumulative sediment yield $(S)$ under FTS and under CS

\begin{tabular}{ccccc}
\hline Treatment & $\begin{array}{c}\text { Mean rainfall intensity } \\
(\mathrm{mm} / \mathrm{min})\end{array}$ & Regression equation & Samples & $R^{2}$ \\
\hline CS & 1.03 & $S=21.201 W^{0.9185}$ & 20 & $0.998^{* *}$ \\
FTS & 1.01 & $S=24.513 W^{0.9323}$ & 20 & $0.998^{* *}$ \\
\hline Note: $^{* *}, P<0.01$ & & &
\end{tabular}

yield increased with increasing runoff with the cumulative sediment yield under FTS being 1.10 times greater than that under CS (Fig. 3). Under the same rainfall-intensity conditions, the $a$ and $b$ coefficients of the power function were significantly larger for the FTS than for the CS, indicating that the dependency of sediment yield on runoff was stronger for the FTS than for the CS.

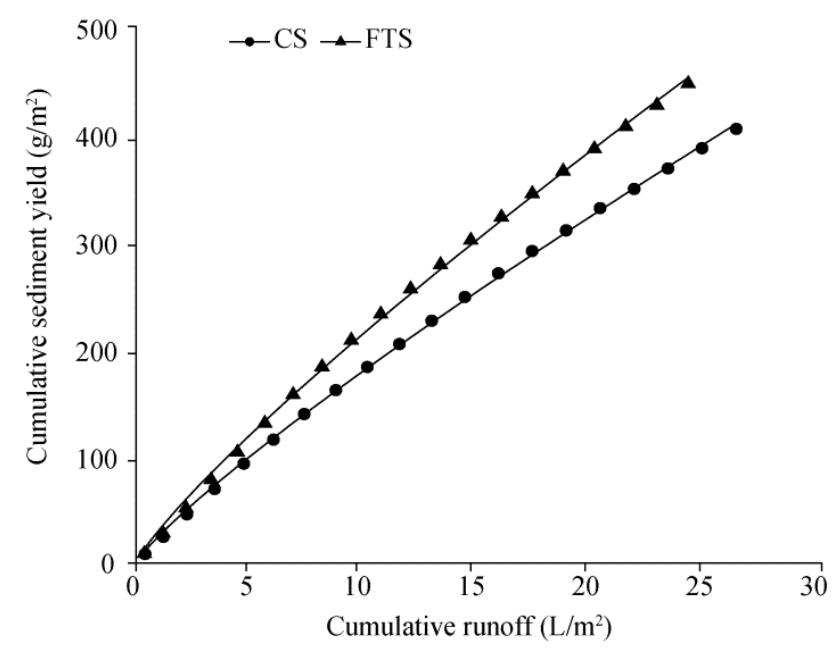

Fig. 3 Relationship between cumulative runoff and cumulative sediment yield under FTS and under CS

\subsection{Size selectivity of the erosion process for splashed and washed particles}

The mean weight diameter (MWD) measurements of washed and splashed sediments under FTS and under CS are illustrated in Figure 4 and the relevant statistical parameters are listed in Table 4. The MWD of splashed sediment ranged from 45.68 to $51.15 \mu \mathrm{m}$ and that of washed sediment from 39.49 to $47.88 \mu \mathrm{m}$ under CS. The MWD of splashed sediment ranged from 46.81 to 54.02 $\mu \mathrm{m}$ and that of washed sediment from 40.92 to $51.61 \mu \mathrm{m}$ under FTS. The mean values of MWD of splashed sediments under CS and under FTS were 48.00 and $49.83 \mu \mathrm{m}$, respectively. The mean values of MWD of washed sediments under CS and under FTS were 43.17 and $44.68 \mu \mathrm{m}$, respectively, suggesting that there were significant differences in the sizes of particles between splash-detached and wash-detached sediments and between CS treatment and FTS treatment.

The MWD values for both splash-detached and wash-detached sediments varied with rain duration (or rain time). The MWD values of splashed sediments were stably higher than the values of washed sediments and also than the values of the original uneroded soils (i.e., approximately $46.8 \mu \mathrm{m}$ ) under both FTS and CS treatments. Three additional notes need mentioning here. First, the MWD values of splashed sediments were more significantly higher than the values of uneroded soils and the MWD values of washed sediments were more significantly higher under FTS than under CS. Second, the MWD values of splashed sediments were significantly higher than those in other two cases (i.e., uneroded soils and washed sediments) only in the middle of the rain time (around $35 \mathrm{~min}$ ) under CS treatment. Third, the MWD values of splashed sediments were significantly higher than those in other two cases (i.e., uneroded soils and washed sediments) at three time intervals (i.e., around $15 \mathrm{~min}$, around $45 \mathrm{~min}$, and around 70 min) under FTS treatment. 
Table 4 Mean weight diameter (MWD) values for splashed and washed sediments under FTS and under CS

\begin{tabular}{cccccc}
\hline \multirow{2}{*}{$\begin{array}{c}\text { MWD value } \\
(\mu \mathrm{m})\end{array}$} & Splash & Wash & & Splash & FTS \\
\cline { 2 - 3 } \cline { 5 - 6 } & 45.68 & 39.49 & & 46.81 & Wash \\
Minimum & 51.15 & 47.88 & & 54.02 & 51.61 \\
Maximum & 48.00 & 43.17 & & 49.83 & 44.68 \\
Mean & & & & \\
\hline
\end{tabular}
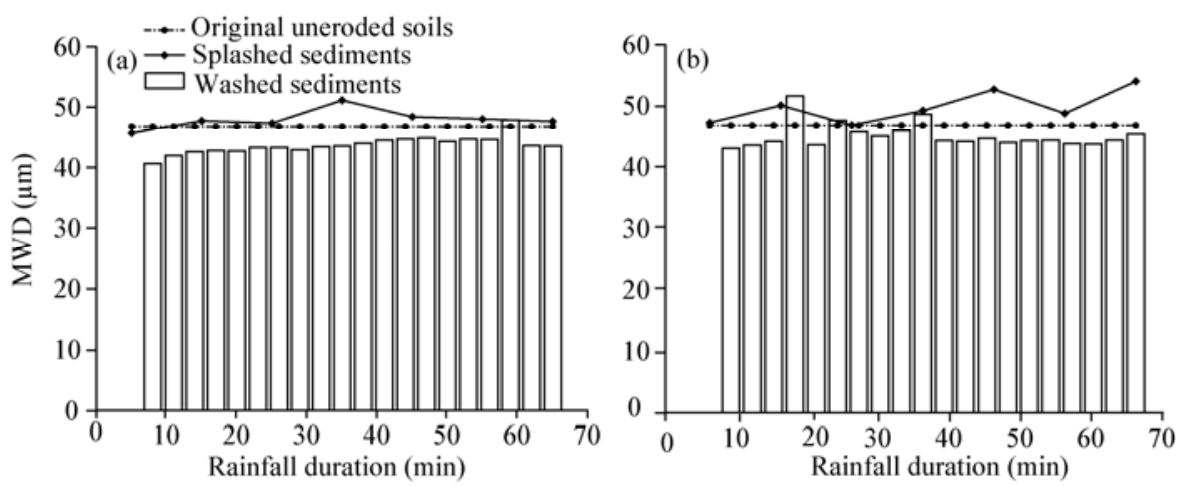

Fig. 4 Mean weight diameter (MWD) of original uneroded soils, splashed sediments, and washed sediments under CS (a) and under FTS (b)

\subsection{Soil erodibility}

The soil bulk density and porosity decreased by $2.93 \%$ and $2.30 \%$, respectively, under FTS compared with those under CS (Table 1). These differences between FTS and CS treatments can definitely affect the erosion-related soil physical properties because soil erodibility is directly related to the soil physical properties (Wischmeier et al., 1971). The soil erodibility factor $K$ in this study was calculated from the rainfall simulation experiments (Table 5). The soil erodibility under FTS treatment was approximately 1.10 times greater than that under CS treatment.

Table 5 Soil erodibility factor $(K)$ calculated from rainfall simulation experiments under FTS and under CS

\begin{tabular}{ccccccc}
\hline Treatment & $\begin{array}{c}\mathrm{A} \\
\left(\mathrm{kg} / \mathrm{m}^{2}\right)\end{array}$ & $\begin{array}{c}\mathrm{MA} \\
\left(\mathrm{kg} / \mathrm{m}^{2}\right)\end{array}$ & $\begin{array}{c}\mathrm{R} \\
\left(\mathrm{MJ} \cdot \mathrm{mm} /\left(\mathrm{m}^{2} \cdot \mathrm{h}\right)\right)\end{array}$ & $\mathrm{LS}$ & $\mathrm{R} \times \mathrm{LS}\left(\mathrm{MJ} \cdot \mathrm{mm} /\left(\mathrm{m}^{2} \cdot \mathrm{h}\right)\right)$ & $\begin{array}{c}K \\
(\mathrm{~kg} \cdot \mathrm{h} /(\mathrm{MJ} \cdot \mathrm{mm}))\end{array}$ \\
\hline \multirow{2}{*}{$\mathrm{CS}$} & 0.40 & 0.40 & 0.11 & 0.78 & & 4.58 \\
& 0.38 & & 0.11 & 0.78 & & 4.99 \\
& 0.43 & & 0.11 & 0.78 & 0.09 & 4.99 \\
\multirow{2}{*}{ FTS } & 0.47 & 0.45 & 0.12 & 0.78 & & \\
& 0.43 & & 0.11 & 0.78 & & \\
& 0.44 & & 0.11 & 0.78 & & \\
\hline
\end{tabular}

Note: A, amount of soil loss; MA, mean amount of soil loss; R, rainfall erosivity; LS, slope length-gradient factor; $K$, soil erodibility.

\section{Discussion}

\subsection{Runoff and deposition processes under FTS and CS}

As shown in Figure 2a, the FTS soil had a lower runoff rate than the CS soil did simply because the FTS soil had a lower bulk density and thus a higher porosity, resulting in a greater infiltration rate (Fig. 2b). This finding is consistent with that by Li et al. (2009) and further confirms the significant effects of FT on runoff and on infiltration. As shown in Figure 2c, the FTS soil had a larger sediment yield rate than the CS soil did although the former (FTS soil) had a lower runoff rate. Our result is in contradiction with previous studies (Giménez and Govers, 2008; Cao et al., 2015; Zhang et al., 2015). The previous studies indicated that a larger runoff rate could carry a greater amount of sediments. This contradiction or difference might be related to the higher erodibility resulted from FTS treatment. Our finding is consistent with that by Wischmeier et al. 
(1978) and suggests that freeze-thaw (FT) processes can effectively decrease the runoff production and increase the sediment yield. Also as shown in Figure 2c, the sediment yield rate under FTS was significantly larger than those under CS during the middle stage (approximately from 15 to $30 \mathrm{~min}$ ) of the rain time and the significantly high rate of sediment rate under FTS may be attributable to potential high erodibility during the middle stage of rain time. As shown in Figure 3, the sediment yield increased with increasing runoff under both FTS and CS, being rather consistent with the data observed in bare field plots (Flanagan et al., 2002; Benik et al., 2003; Zhao et al., 2013). The power-function relationships between cumulative runoff and sediment yield both under FTS and CS presented in this study lend a further support to the early reported relationships (Wang et al., 2010; Xiao et al., 2011; Xu et al., 2015).

\subsection{Size-selectivity of erosion under FTS and CS}

The MWD of splashed sediments was larger than that of washed sediments and also larger than that of uneroded soil both under FTS and CS, being supportive to some previous studies showing that the splash-detached particles are coarser than wash-detached particles (Sutherland et al., 1996; Wan and El-Swaify, 1998). However, our results differ from other previous studies. For example, Issa et al. (2006) demonstrated that the size of splash-detached particles was similar to that of wash-detached particles. A reconcilable explanation for the differences between our results and those of Issa et al. (2006) is that the rainfall intensity can affect sediment yield more effectively through runoff generation than through raindrop splashing (Meyer, 1981). That is, the high rainfall intensity in the case of Issa et al. (2006) first splash-detached the particles and then wash-transported the detached particles, thus resulting in the observed similar sizes between splash and wash. Under similar rainfall conditions, the values of the runoff rate under CS $(0.13$ to $0.5 \mathrm{~mm} / \mathrm{min})$ were not significantly different from those under FTS $(0.12$ to $0.46 \mathrm{~mm} / \mathrm{min})$. However, the MWD values of wash-detached particles under FTS were significantly larger than those under CS in the case of interrill erosion. This indicated that runoff was not the main factor affecting particle selectivity in our experiment. The differences in MWD values between the two treatments (FTS and CS) in the case of interrill erosion may be resulted from the changes in the soil properties caused by FT processes.

\subsection{Evaluation of soil erodibility under FTS and CS}

This study showed that the soil erodibility under FTS was larger (by approximately 1.10 times) than that under CS (Table 4). The difference in soil erodibility between FTS and CS treatments was primarily resulted from the different soil texture caused by these two different treatments. That is, seasonal FT cycles caused by seasonal and even diurnal changes in soil temperature and moisture can definitely change the soil physical properties and the changes include the decrease in soil bulk density and the increase in soil porosity (Zhu and Zhu, 1991). Specifically, the water (liquid or vapor) within the soil pores can forms a variety of ice intrusions when the soil is frozen, leading to an expansion in the soil volume. The expanded soil starts to thaw and develops a larger porosity when the temperature rises, resulting in an increase in the soil erodibility (Gatto, 2000). This study used the value of $K$ to assess the soil erodibility under FTS and CS treatments. The relationships between runoff and sediment yield have often been used to assess the soil erodibility and the absolute value of the regression coefficient $a$ was also advocated to assess the soil erodibility (Pan and Shangguan, 2006; Wang et al., 2014). The ratio of the absolute values of $K$ between the FTS and the CS was 1.10 and the ratio of the absolute $a$ values between FTS and CS was 1.15 . This suggests that both $K$ ratio and $a$ ratio can be used to evaluate the soil erodibility. However, it should be noted that the ratio of the absolute value of $a$ is not equivalent to the soil erodibility factor $K$. Instead, the value of $K$ only reflects the average conditions of a certain soil, while the value of $a$ may reflect changes in the cumulative amount of sediment eroded under different treatments (FTS and CS). Therefore, the absolute value of $a$ could be used to evaluate soil erodibility to predict the amount of lost soil more accurately. 


\section{Conclusions}

The runoff of the FTS decreased by $8 \%$ compared to that of the CS, and the total sediment yield of the FTS was 1.10 times that of the CS. The relationships between cumulative runoff and sediment yield both under FTS and CS can be fitted well with power functions. Significant differences in MWD values were observed for washed particles and splashed particles between FTS and CS treatments. Specifically, the mean MWD values under FTS were higher than those under CS for both washed sediments and splashed sediments. The ratio of the absolute $a$ values between FTS and CS was 1.15 , being roughly correspondent with the ratio of $K$ between the two treatments. Therefore, the parameter $a$ of the power function between cumulative runoff and sediment yield could be an acceptable indicator for expressing the soil erodibility.

\section{Acknowledgements}

This research was supported by the National Basic Research Program of China (2016YFC040240X), the National Natural Science Foundation of China (41471226, 41330858), and the Independent Research Foundation of State Key Laboratory Base of Eco-Hydraulic Engineering in Arid Area (2016KFKT-8). In addition, we thank the reviewers for their useful comments and suggestions.

\section{References}

Asadi H, Ghadiri H, Rose C W, et al. 2007a. Interrill soil erosion processes and their interaction on low slopes. Earth Surface Processes and Landforms, 32(5): 711-724.

Asadi H, Ghadiri H, Rose C W, et al. 2007b. An investigation of flow-driven soil erosion processes at low streampowers. Journal of Hydrology, 342(1-2): 134-142.

Benik S R, Wilson B N, Biesboer D D, et al. 2003. Performance of erosion control products on a highway embankment. Transactions of the ASAE, 46(4): 1113-1119.

Berger C, Schulze M, Rieke-Zapp D, et al. 2010. Rill development and soil erosion: a laboratory study of slope and rainfall intensity. Earth Surface Processes and Landforms, 35(12): 1456-1467.

Cao L X, Liang Y, Wang Y, et al. 2015. Runoff and soil loss from Pinus massoniana forest in southern China after simulated rainfall. Catena, 129: 1-8.

Farenhorst A, Bryan R B. 1995. Particle size distribution of sediment transported by shallow flow. Catena, 25(1-4): 47-62.

Flanagan D C, Chaudhari K, Norton L D. 2002. Polyacrylamide soil amendment effects on runoff and sediment yield on steep slopes: Part I. Simulated rainfall conditions. Transactions of the ASAE, 45(5): 1327-1337.

Gatto L W. 2000. Soil freeze-thaw-induced changes to a simulated rill: potential impacts on soil erosion. Geomorphology, 32(12): $147-160$.

Giménez R, Govers G. 2008. Effects of freshly incorporated straw residue on rill erosion and hydraulics. Catena, 72(2): 214223.

Hunt B, Walmsley T J, Bradshaw A D. 1991. Importance of soil physical conditions for urban tree growth. In: Hodge S J. Research for Practical Arboriculture. Forestry Commission Bulletin. London: HMSO, 51-62.

Issa O M, Le Bissonnais Y, Planchon O, et al. 2006. Soil detachment and transport on field- and laboratory-scale interrill areas: erosion processes and the size-selectivity of eroded sediment. Earth Surface Processes and Landforms, 31(8): 929-939.

Jiang F S, Huang Y H, Lin J S, et al. 2014. Effects of slope gradient and rainfall intensity on particle size composition of erosion sediment from colluvial deposits of benggang. Acta Pedologica Sinica, 51(5): 974-982. (in Chinese)

Jing G C, Ren X P, Liu X J, et al. 2008. Relationship between freeze-thaw action and soil moisture for Northeast black soil region of China. Science of Soil and Water Conservation, 6(5): 32-36. (in Chinese)

Kirkby M J. 1980. Modelling water erosion processes. In: Kirkby M J, Morgan R P C. Soil Erosion. Chichester, Great Britain: Wiley, 183-196.

Le Bissonnais Y. 1996. Aggregate stability and assessment of soil crustability and erodibility: I. Theory and methodology. European Journal of Soil Science, 47(4): 425-437.

Li G Y, Fan H M. 2014. Effect of freeze-thaw on water stability of aggregates in a black soil of northeast China. Pedosphere, 24(2): 285-290.

Li Q, Liu G B, Xu M G, et al. 2013. Effect of seasonal freeze-thaw on soil anti-scouribility and its related physical property in hilly loess plateau. Transactions of the Chinese Society of Agricultural Engineering, 29(17): 105-112. (in Chinese) 
Meyer L D. 1981. How rain intensity affects interrill erosion. Transactions of the American Society of Agricultural Engineers, 24(6): 1472-1475.

Li Z, Wu P T, Feng H, et al. 2009. Simulated experiment on effect of soil bulk density on soil infiltration capacity. Transactions of the CSAE, 25(6): 40-44. (in Chinese)

Meyer L D. 1981. How rain intensity affects interrill erosion. Transactions of the ASAE, 24(6): 1472-1475.

Meyer L D, Line D E, Harmon W C. 1992. Size characteristics of sediment from agricultural soils. Journal of Soil and Water Conservation, 47(1): 107-111.

Øygarden L. 2000. Soil erosion in small agricultural catchments, South-eastern Norway. PhD Dissertation. Norway: Norwegian University of Agricultural Sciences, 8.

Pan C Z, Shangguan Z P. 2006. Runoff hydraulic characteristics and sediment generation in sloped grassplots under simulated rainfall conditions. Journal of Hydrology, 331(1-2): 178-185.

Ran Q H, Su D Y, Li P, et al. 2012. Experimental study of the impact of rainfall characteristics on runoff generation and soil erosion. Journal of Hydrology, 424-425: 99-111.

Sahin U, Anapali O. 2007. The effect of freeze-thaw cycles on soil aggregate stability in different salinity and sodicity conditions. Spanish Journal of Agricultural Research, 5(3): 431-434.

Sharma P P. 1996. Interrill erosion. In: Agassi M. Soil Erosion Conservation and Rehabilitation. New York: Marcel Dekker, 125-152.

Shi Z H, Fang N F, Wu F Z, et al. 2012. Soil erosion processes and sediment sorting associated with transport mechanisms on steep slopes. Journal of Hydrology, 454-455: 123-130.

Sutherland R A, Wan Y, Ziegler A D, et al. 1996. Splash and wash dynamics: an experimental investigation using an oxisol. Geoderma, 69(1-2): 85-103.

Wan Y, El-Swaify S A. 1998. Characterizing interrill sediment size by partitioning splash and wash processes. Soil Science Society of America Journal, 62(2): 430-437.

Wang B, Zheng F L, Römkens M J M, et al. 2013. Soil erodibility for water erosion: a perspective and Chinese experiences. Geomorphology, 187: 1-10.

Wang G Q, Wu B B, Zhang L, et al. 2014. Role of soil erodibility in affecting available nitrogen and phosphorus losses under simulated rainfall. Journal of Hydrology, 514: 180-191.

Wang L, Tang L L, Wang X, et al. 2010. Effects of alley crop planting on soil and nutrient losses in the citrus orchards of the Three Gorges Region. Soil and Tillage Research, 110(2): 243-250.

Wang S J. 2004. Characteristics of freeze and thaw weathering and its contribution to sediment yield in middle Yellow River Basin. Bulletin of Soil and Water Conservation, 24(6): 1-5. (in Chinese)

Wischmeier W H, Johnson C B, Cross B V. 1971. A soil erodibility monograph for farmland and construction sites. Journal of Soil and Water Conservation, 26(5): 189-193.

Wischmeier W H, Smith D D. 1978. Predicting Rainfall Erosion Losses: A Guide to Conservation Planning. Agriculture Handbook Vol. 537. Washington, D.C: United States Department of Agriculture, 5-8, 58.

Xiao P Q, Yao W Y, Shen Z Z, et al. 2011. Experimental study on erosion process and hydrodynamics mechanism of alfalfa grassland. Journal of Hydraulic Engineering, 42(2): 232-237. (in Chinese)

Xu G C, Li Z B, Li P. 2013. Fractal features of soil particle-size distribution and total soil nitrogen distribution in a typical watershed in the source area of the middle Dan River, China. Catena, 101: 17-23.

Xu G C, Tang S S, Lu K X, et al. 2015. Runoff and sediment yield under simulated rainfall on sand-covered slopes in a region subject to wind-water erosion. Environmental Earth Sciences, 74(3): 2523-2530.

Xu X Z, Wang J C, Zhang L X. 2001. Geocryology Physics. Beijing: Science Press, 4. (in Chinese)

Young R A. 1980. Characteristics of eroded sediment. Transactions of the ASAE, 23(5): 1139-1142.

Yu D S, Shi X Z, Weindorf D C. 2006. Relationships between permeability and erodibility of cultivated acrisols and cambisols in subtropical China. Pedosphere, 16(3): 304-311.

Zhang J G, Liu S Z, Yang S Q. 2007. The classification and assessment of freeze-thaw erosion in Tibet. Journal of Geographical Sciences, 17(2): 165-174.

Zhang L T, Gao Z L, Yang S W, et al. 2015. Dynamic processes of soil erosion by runoff on engineered landforms derived from expressway construction: a case study of typical steep spoil heap. Catena, 128: 108-121.

Zhao X N, Wu P T, Chen X L, et al. 2013. Runoff and sediment yield under simulated rainfall on hillslopes in the loess plateau of China. Soil Research, 51(1): 50-58.

Zhu X M, Zhu Y Z. 1991. An Introduction to Soil and Environment in Chinese Loess Plateau. Beijing: Science Press, $273-279$. (in Chinese) 